\title{
PSYCHE.
}

\section{THE HABITS OF MYRMECOPHILA NEBRASCENSIS BRUNER.*}

BY WILliAM MORTON WHEELER, AUSTIN, TEXAS.

Among the many insects now known to live as guests in the nests of ants the diminutive crickets of the genus Myrmecophila are in several respects remarkable. First, they are cited as the only members of the great Orthopteran order that have come to live with the most social of the Hymenoptera $\dagger$; second, the males of the species of Myrmecophila have long been all but unknown, and third, the nature of the relationship of these little Gryllids to their emmet hosts has not been determined up to the present time.

In the November number of Psyche for I899, Mr. Scudder published a monograph of the known North American species of Myrmecophila. This will undoubtedly encourage further work on this interesting genus along taxonomic lines. In the present paper I wish to call attention to the peculiar habits of one of the species, $M$. neb-

\footnotetext{
* Contributions from the Zoological Laboratory of the University of Texas. No. 7. Director, W. M. Wheeler.

$\uparrow$ This statement now requires qualification. In a forthcoming paper I shall describe another Orthopteran genus, represented by a diminutive cockroach, which lives as a myrmecophile in the fungus gardens of the leaf-cutting ant of Texas (Atta fervens Say).
}

rascensis Bruner, which is very common in the vicinity of Austin, Texas. Here it may be found in the nests of no less than five very different species of ants. It is most abundant in company with Formica fusca, var. neorufibarbis Mayr sometimes as many as 20 or 30 individuals occurring in a single nest - less abundant in the nests of the Texan agricultural ant (Pogonomyrmex barbatus Sm.) - and rare in the nests of Camponotus castaneus Latr., the Ponerine Pachycondyla harpax Fab. and a species of Cremastogaster. Its true host in this vicinity is undoubtedly $F$. fusca var. neorufibarbis, which digs its galleries under stones on moderately moist hillslopes in the shade of the cedars and live oaks. Since nests of all the different species of ants above mentioned may be found very near one another, it is probable that the crickets occasionally seen in the nests of Pachycondyla and Camponotus are vagrants that have invaded strange territory.

These data on the occurrence of $M$. nebrascensis are of some interest since they extend both the geographical and symbiotic range of the species. Hitherto, according to the data accumulated 
by Mr. Scudder,* it was known to occur in Minnesota (Lugger), Nebraska (Bruner) and New Mexico (Cockerell). The addition of one of the Gulf states, in which no members of the genus had been found, carries the species to its southernmost boundary. Heretofore it has been taken only in the nests of Formica exsectoides Forel (in New Mexico) and with some ants which Bruner incorrectly referred to $F$. rufa. Pergande believes that it "equally frequents the colonies of Formica puberula Em., Form. integroides Em., Form. rubiginosa $\mathrm{Em}$. and possibly other forms belonging to the great Rufa group." $\dagger$

The males of the European species of Myrmecophila are so rare as to be almost unknown. Scudder says (loc. cit., p. 428): "Although two species of the genus are known in Europe, and one of them is not uncommon, Brunner von Wattenwyl says the male is unknown to him, Saussure has but once seen one, and this was destroyed before he could describe the genitalia, and Fischer of Freiburg has seen the males of one species only, and in his classical work refers to it only by the words: "lam. supraanalis mihi non rite visa." It is, however, figured in Cuvier's Regne Anim., Disc. ed. pl. 82, fig 2." Even Wasmann, who has devoted special study to the guests of ants, cites the medium sized individuals of the European $M$. acervorum as doubtfully be-

\footnotetext{
*loc. cit. p. 427 .
}

† Scudder, loc. cit. p. $4^{28}$. longing to the male sex.* In the United States, however, the males of Myrmecophila are not uncommon. Among forty specimens Scudder found sixteen males, and these represented all but one of the five North American species.

The males of $M$. nebrascensis are very common at Austin. They bear to the females, I should say, the ratio of about one to seven or eight. That the somewhat smaller individuals without ovipositors and with a large, apically cleft subgenital plate are really the males is shown in sections. During April and May the testes, in active spermatogenesis, together with a huge accessory gland consisting of a radiating tuft of tubules, fill out nearly the whole abdominal cavity of the insect. The gland must have some important function connected with reproduction but this could not be determined.

At this same period of the year the abdomen of the female Myrmecophila is found to contain a few very large elliptical white eggs, in form and size not unlike the eggs of the ants among which the crickets live. I have not been able to observe the insect in the act of ovipositing. She probably thrusts her eggs into the moist compact soil that forms the walls of the galleries of the ants' nest. The eggs must hatch about the first of June, as I have seen the young, about one fifth to one fourth grown by

\footnotetext{
* Kritisches Verzeichniss der myrmekophilen und termitophilen Arthropoden. Berlin, r894, p. I76.
} 
June 22 nd. They are paler and relatively somewhat narrower than the adults.

My observations on the habits of Myrmecophila began early in March of the present year. The little crickets were taken from the Formica nests and placed in artificial nests of Pogonomyrmex, an ant of slower movements and in many other respects more satisfactory for purposes of observation than the Formica. At first I used nests consisting of largemouthed glass jars containing some earth in which the ants readily dug their galleries and chambers, sometimes next to the glass; but quite as often where their occupants could not be seen. The crickets placed on the earth at once crept down into the galleries and could be seen only from time to time moving about unmolested among the ants and along the walls of the burrows. This did not satisfy me, so I abandoned these earthen nests for cement nests of the Janet pattern. I had no occasion to regret this change as it enabled me to observe the insects for hours at a time without disturbing them, especially in the lamplight, of which both the ants and the crickets seem very fond. The following from my notebook is one of a number of similar observations.

April 3 rd. Placed in the Pogonomyrmex nest twenty Myrmecophilas, eight or ten of which had been squeezed or had lost one or both saltatory legs during capture. All the disabled individuals were at once seized and dispatched in so vindictive a manner, that I could not doubt that the ants were irritated by the pungent neorufibarbis nest-odor still clinging to the crickets. In an instant all the ants in the compartment of the nest had gathered in little groups, each devouring a Myrmecophila. The uninjured crickets made not the slightest attempt to escape but felt themselves perfectly at home as soon as they set foot on the floor of the nest. 'Their adaptation to a new-nest and to an ant of larger size and belonging to an entirely different subfamily from their former host, was immediate and complete. With constantly vibrating antennae they began dodging in and out among the little groups of assembled ants. From time to time one of them would be seen cautiously approaching an ant, that was busy with its dinner of Myrmecophila, and fall to nibbling at its legs or the tip of its abdomen. There could be no doubt that the cricket derived some benefit from the oily secretion covering the surface of the ant's body. At first the ant disregarded this nibbling, which probably resembles the attentions of the toilet habitually received from sister ants, but the cricket's scraping mandibles and maxillae soon grew annoying and the ant would either move away or turn its head, open its mandibles and make a lunge at the Myrmecophila like a large dog annoyed by a puppy. But before the huge mandibles had closed, the cricket was far away, already nibbling at the abdomen of some other ant. The cricket can get at only the legs and abdomen of its host, since the spreading legs prevent it from reaching 
the thorax. It often stands on its hind legs, as represented in the figure, and places its fore legs on the ant's leg, in order to reach the femur or tibia. For very obvious reasons, it avoids nibbling at or even approaching the ant's head. It is always alert, as if perpetually aware of danger and ready to dodge at the slightest movement made by the ant.
The crickets do not derive all their sustenance from cleansing their hosts. In earthen nests they are often seen haunting even the galleries that have been abandoned by the ants, scrutinizing the walls and nibbling at them from time to time. There can be no doubt that they find here the same substance which covers the ants, for the walls of the galleries of a populous nest soon be.

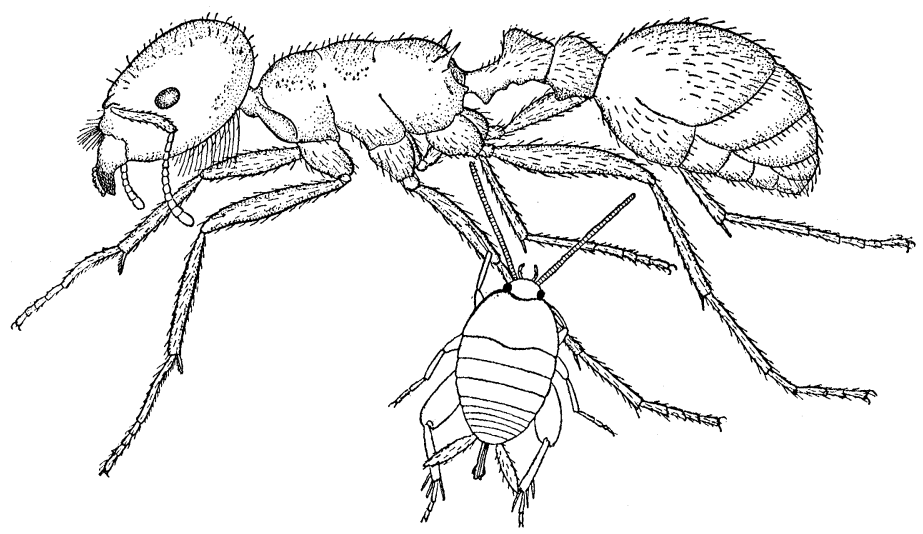

Myrmecophila in the act of feeding on the integumentary secretion of the agricultural ant.

Occasionally in the narrow confines of an artificial nest the ants do succeed in capturing and devouring one of their vigilant little guests, but the fact, that of the eleven sound crickets left after the above observation was made, eight were still alive June $22 \mathrm{nd}$, when I had to discontinue my observations for the summer, shows that the crickets are extremely expert in keeping out of danger. The attitude of the ants during all this time underwent no change so far as I could observe, for they would still occasionally make lunges at the crickets. come greasy from the attrition of the constantly passing ants. Sometimes the crickets may be seen nibbling at dead ants that have been temporarily abandoned in the galleries or placed on the kitchen-midden of the nest. The intestine of a Myrmecophila which I dissected was found to contain oil-globules and a granular whitish substance. It is possible that one or both of these may be the products of integumentary glands like those described by Janet.*

* Sur le Système glandulaire des Fourmis. Compt. Rend. hebd. de l' Acad. Sci. T. ir8. p. 989 , r894. 
It is an established fact that ants when moving to a new nest will take with them certain of their guests like their Aphides, and the singular beetles of the genera Claviger, Paussus, etc. Myrmecophila can lay claim to no such consideration. When a colony of Formica neorufibarbis moves, the crickets are all left behind. The heavy floods of the past spring gave me an excellent opportunity to convince myself of the truth of this statement. Many of the neorufibarbis nests which I was in the habit of visiting, were submerged during the night by a rapid rise of one of the creeks near Austin. The following day, when the water had subsided, I found that the nests had been completely deserted by the ants, but nearly all of them still contained numerous Myrmecophila wandering in and out of the galleries under the stones as if nothing had happened. I have also seen the crickets left behind in other neorufibarbis nests which were on higher ground and had been deserted for reasons unknown to me. These observations may explain a note quoted by Mr. Scudder concerning $M$. oregonensis Bruner. Dr. Fletcher informed him that this species is " common in British Columbia under almost every slab of wood in some places, whether there are ants there or not." I doubt the occurrence of Myrmecophila outside of ants' nests.

It is evident from the facts above recorded that the ants would gladly forego the company of their little nest-mates, but unless they resort to moving the whole colony, they are compelled to tolerate them for a very simple reason. The ants with their long bodies, incapable of much lateral flexure, always walk or run in long, straight or sinuous paths, and are quite unable to turn sharply about, whereas the short-bodied crickets move in a complicated zig-zag path made up of very short lines and abrupt angles. This seems to be the key to the symbiosis of the two insects: the ant and the cricket manage to get on together in the limited space of an ants' nest because they have very different, and, as it were, interdigitating modes of progression. Since the ants are quite able to clean themselves and one another and even take delight and spend much time in this employment, they probably derive little or no advantage from their cricket guests. The crickets, however, cannot get on without the ants and the greasy walls of their burrows. The symbiosis is therefore of a unilateral type and would seem to belong in the category of relationships called "Metoekie" or "Synoekie" by Wasmann. It is, in fact, a relationship but slightly in advance of that of the Collembolan $C y$ phodeira (Beckia) albinos Nic. which appears to obtain its entire sustenance from the walls of the ants' burrows without extending its attentions to the integument of the ants.

University of Texas, Austin, Tex., June 2 2nd, 1900.

* Die Myrmekophilen und Termitophilen, Compt. Rend. des Séances du 3 me Congr. internat. Zool. Leyde 16-2I Sept. 1895. Leyden. 1896. p. 412. 

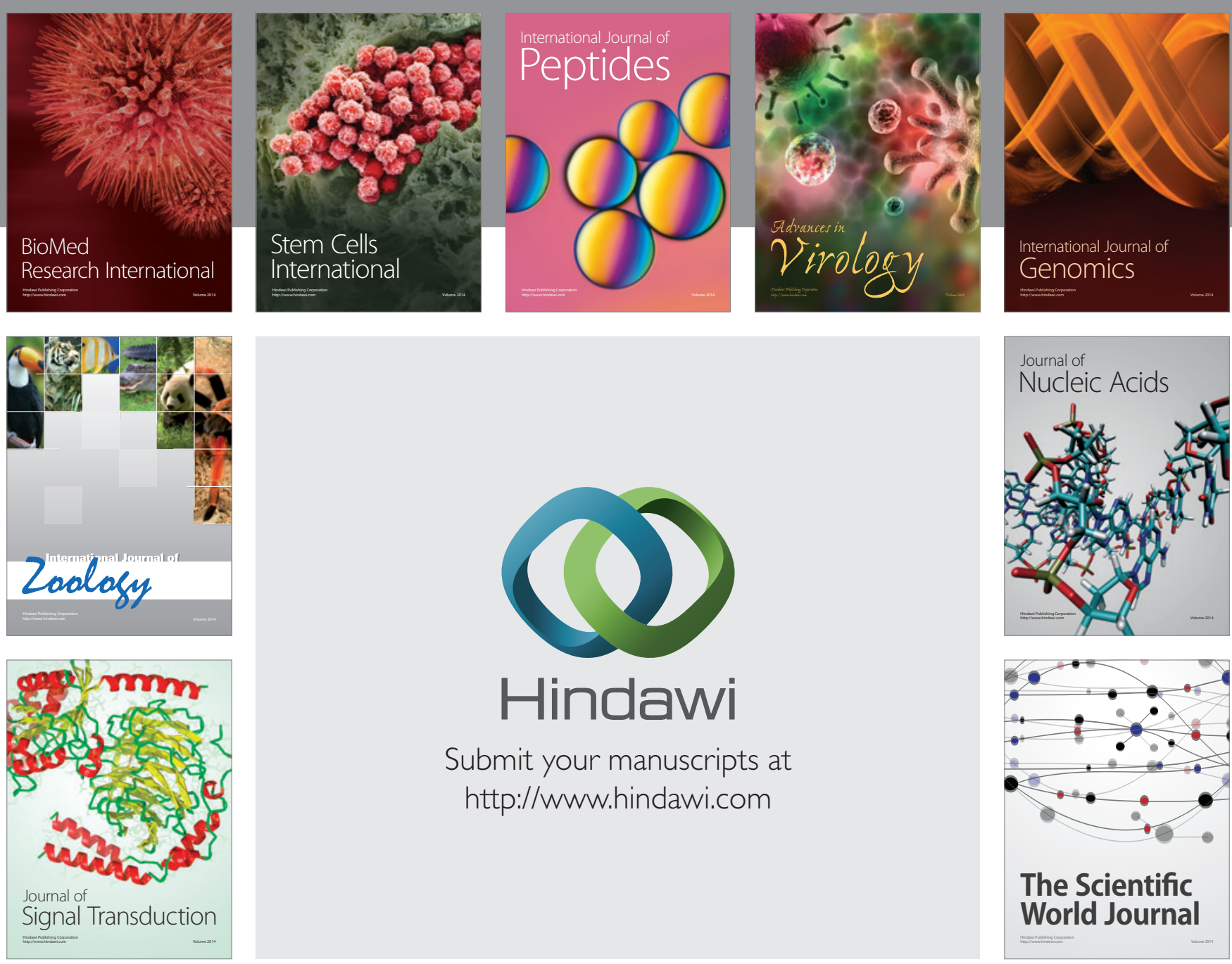

Submit your manuscripts at

http://www.hindawi.com
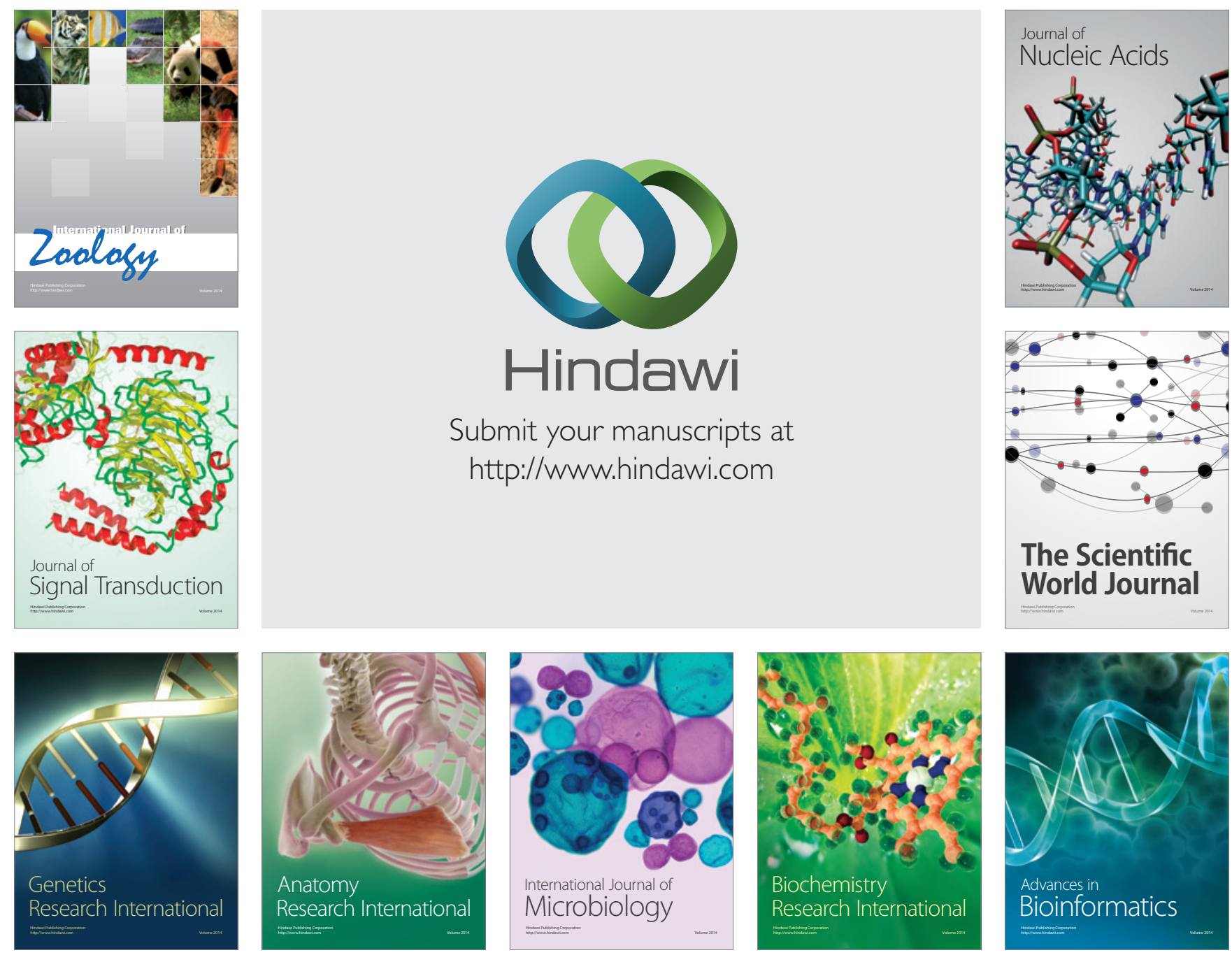

The Scientific World Journal
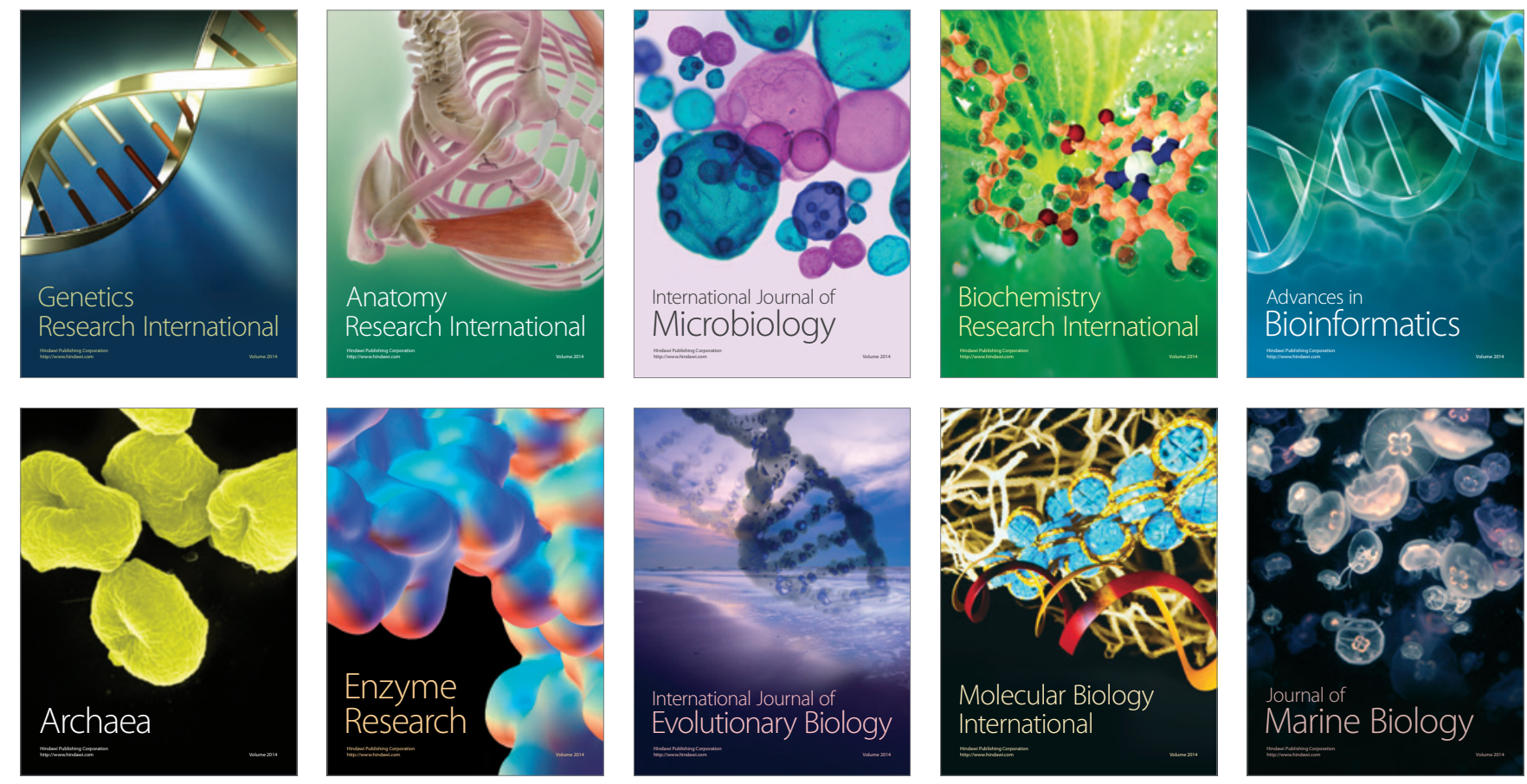